\title{
Effects of sintering temperature on structure, magnetic and dielectric properties of $\mathrm{La}_{0.5} \mathrm{Sr}_{0.5} \mathrm{Fe}_{0.9} \mathrm{Mn}_{0.05} \mathrm{Ti}_{0.05} \mathrm{O}_{3}$ material
}

\author{
Erfan Handoko ${ }^{1, *}$, Iwan Sugihartono ${ }^{1}$, Riser Fahdiran ${ }^{1}$, Zulkarnain Jalil ${ }^{2}$, Sitti Ahmiatri Saptari ${ }^{3}$, and Mangasi A M ${ }^{1}$ \\ ${ }^{1}$ Universitas Negeri Jakarta, Dept. of Physics, Jalan Rawamangun Muka 13220, Jakarta, Indonesia \\ ${ }^{2}$ Syiah Kuala University, Dept. of Physics, Banda Aceh, Indonesia \\ ${ }^{3}$ Universitas Islam Negeri Syarif Hidayatullah, Dept. of Physics, Jakarta, Indonesia
}

\begin{abstract}
We have investigated structure, magnetic and dielectric of $\mathrm{La}_{0.5} \mathrm{Sr}_{0.5} \mathrm{Fe}_{0 .} \mathrm{Mn}_{0.05} \mathrm{Ti}_{0.05} \mathrm{O}_{3}$ (LSFMTO) system using ultrasonic mixing method. LSFMTO system is driven by $40 \mathrm{kHz}$ frequency and calcinate process up to $750^{\circ} \mathrm{C}$ for 30 minutes. Then sintering process also carried out by systematic various of temperature 900 ${ }^{\circ} \mathrm{C}, 1000^{\circ} \mathrm{C}$, and $1100^{\circ} \mathrm{C}$ respectively, as same time previously. Very interestingly, the LSFMTO system exhibits ferroelectric $(\mathrm{La}, \mathrm{Sr})(\mathrm{Fe}, \mathrm{Mn}, \mathrm{Ti}) \mathrm{O}_{3}$ and ferromagnetic $\mathrm{SrFe}_{12} 0_{19}$ properties and minor phase $\mathrm{La}_{2} \mathrm{O}_{3}$ by XRD interpretation analyzation. We have also carried out the measurement of LSFMTO system using a systematic applied the external magnetic field from 0 to $1 \mathrm{~T}$ and the electric polarization from 0 to $50 \mathrm{kV} / \mathrm{m}$. The hysteresis curve of LSFMTO system shows the electricty coercive (Ec) increases while the saturation polarization $(\mathrm{Pc})$ and the remanent polarization are tendency constant at the magnetic strength of $0.12 \mathrm{~T}$. We believed that our finding of LSFMTO system is potensial to multiferroic material as magnetic sensor application.
\end{abstract}

\section{Introduction}

In recent years multiferroic composites have been a lot of interest in class of multi-functional materials which exhibit strong magnetoelectric (ME) [1-4]. The ME materials can couple with stimulating either by electric or magnetic fields [5-10]. Perovskite structure with $\mathrm{ABO}_{3}$ system such as $\mathrm{BaTiO}_{3}$ and $\mathrm{LaMnO}_{3}$ is considered to be a good ferroelectric and $(\mathrm{Ba}, \mathrm{Sr}) \mathrm{Fe}_{12} \mathrm{O}_{19}$ is as a permanent magnet with high thermal stability and mainly used as a magnetic data storage [11-15]. Multiferroic composites in which ferroelectricity and ferromagnetism materials can result Magnetoelectric (ME) effect. Especially, $(\mathrm{La}, \mathrm{Sr}) \mathrm{MnO}_{3}$ or LSMO attracts a lot of attention because the manganites form a class of magnetic materials [1619]. In the present paper, we studied the different sintering temperature of $\mathrm{La}_{0.5} \mathrm{Sr}_{0.5} \mathrm{Fe}_{0.9} \mathrm{Mn}_{0.05} \mathrm{Ti}_{0.05} \mathrm{O}_{3}$ (LSFMTO) system that was prepared by solid state method. The preparation method affects the morphological, dielectric and magnetic properties of $\mathrm{La}_{0.5} \mathrm{Sr}_{0.5} \mathrm{Fe}_{0.9} \mathrm{Mn}_{0.05} \mathrm{Ti}_{0.05} \mathrm{O}_{3}$ (LSFMTO) system. In a similar way, we study not only the substitution of the Fe by $\mathrm{Mn}$ and $\mathrm{Ti}$ ions, but also effect of the substitution of the Lanthanum by more $\mathrm{Sr}$ ions. We also have investigated magnetic and electric coercive behavior of LSFMTO.

\section{Experimental method}

Perovskite structure with $\mathrm{La}_{0.5} \mathrm{Sr}_{0.5} \mathrm{Fe}_{0.9} \mathrm{Mn}_{0.05} \mathrm{Ti}_{0.05} \mathrm{O}_{3}$ (LSFMTO) was synthesized by ultrasonic mixing method from $\mathrm{La}_{2} \mathrm{O}_{3}, \mathrm{SrCO}_{3}, \mathrm{Fe}_{2} \mathrm{O}_{3}, \mathrm{MnCO}_{3}$, and $\mathrm{TiO}_{2}$. The nominal composition and the stoichiometry of $\mathrm{La}_{0.5} \mathrm{Sr}_{0.5} \mathrm{Fe}_{0.9} \mathrm{Mn}_{0.05} \mathrm{Ti}_{0.05} \mathrm{O}_{3}$ were mixed in glass with aquades by $40 \mathrm{kHz}$ frequency. Then, the mixture was calcinated up to $750^{\circ} \mathrm{C}$ for 30 minutes. And sintering process also carried out by systematic various of temperature $900{ }^{\circ} \mathrm{C}, 1000{ }^{\circ} \mathrm{C}$, and $1100{ }^{\circ} \mathrm{C}$ respectively, with time preparation is same previously. $\mathrm{La}_{0.5} \mathrm{Sr}_{0.5} \mathrm{Fe}_{0.9} \mathrm{Mn}_{0.05} \mathrm{Ti}_{0.05} \mathrm{O}_{3}$ powders were obtained. Powder X-ray diffraction (XRD) patterns were meansured by Phillips diffractometer using $\mathrm{CoK}_{\square}$ radiation and with JEOL JSM 5310LV scanning electron microscope (SEM) observed the microstructures of LSFTMO. The magnetic datas were recorded at room temperature with Permagraph in maximum magnetic field $2 \mathrm{~T}$ to find magnetic properties of LSFTMO. The electric polarization were used Electrometer Keithley.

\section{Results and discussion}

\subsection{Microstructure}

Fig 1. Show the results of XRD pattern of LSFMTO sample with various of temperature are multi phase of ferroelectric $\quad(\mathrm{La}, \mathrm{Sr})(\mathrm{Fe}, \mathrm{Mn}, \mathrm{Ti}) \mathrm{O}_{3}$, ferromagnetic $\mathrm{SrFe}_{12} \mathrm{O}_{19}$ properties and minor phase $\mathrm{La}_{2} \mathrm{O}_{3}$.

\footnotetext{
* Corresponding author: erfan@unj.ac.id
} 

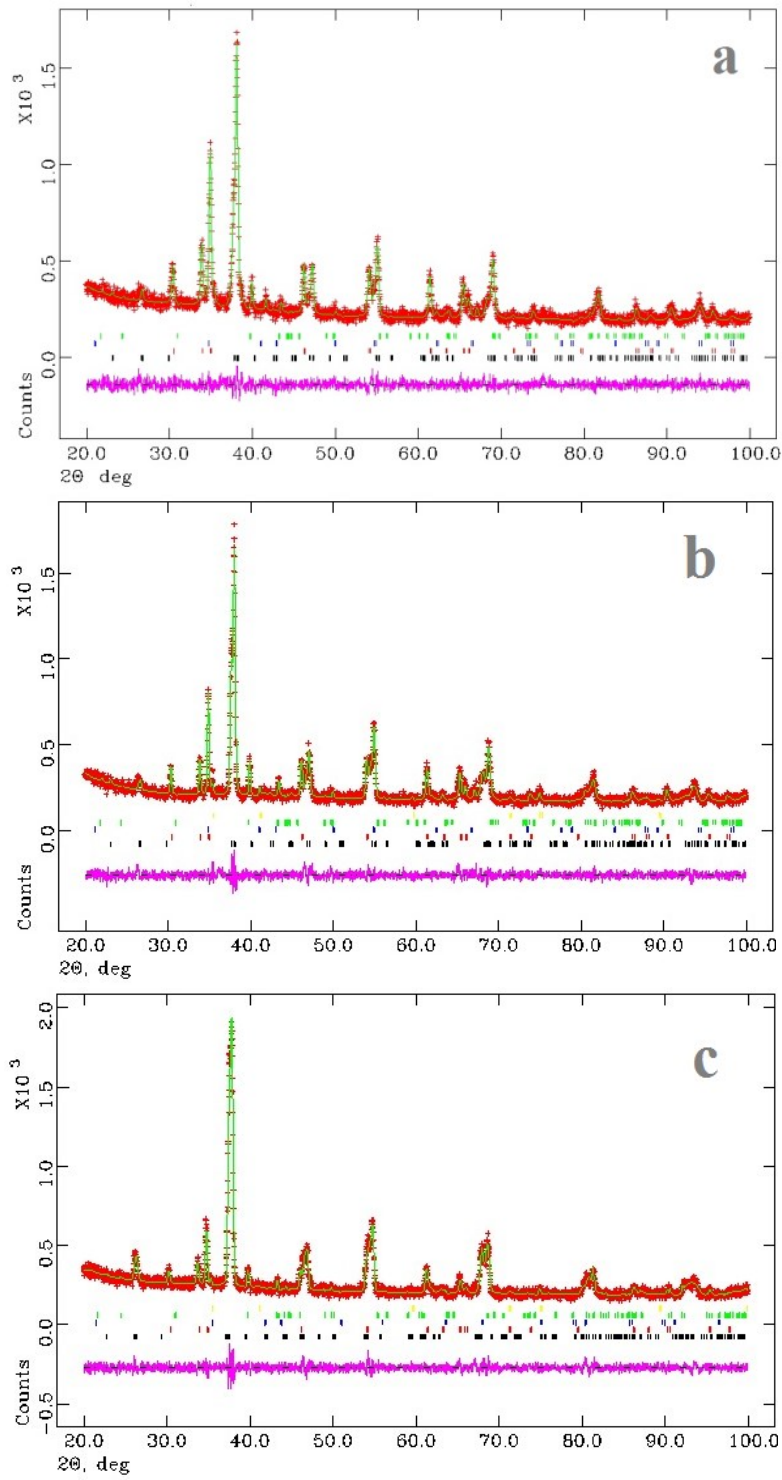

Fig 1. Calculated result (solid lines) of XRD patterns of LSFMTO samples were calcinated up to $750^{\circ} \mathrm{C}$ for 30 minutes and sintered systematic various of temperature (a). $900{ }^{\circ} \mathrm{C}$, (b). $1000^{\circ} \mathrm{C}$, and (c). $1100^{\circ} \mathrm{C}$.

LSFMTO samples are identified in all heat treatment as the main phase. Includes $\mathrm{SrFe}_{12} \mathrm{O}_{19}$ and $\mathrm{La}_{2} \mathrm{O}_{3}$ as the second phases. From x-ray diffraction data refinement can be determined the quantitative number of phases in the measured material. Table 1 shows the measured magnetic properties. The weight fraction increasing of primary phase indicates that the main phase greatly affected by magnetic and dielectric properties.

Table 1. Refined structure results of LSFMTO were sintered systematic various of temperature.

\begin{tabular}{|c|c|c|c|}
\hline \multirow{2}{*}{ Sample } & \multicolumn{3}{|c|}{ Temperature $\left({ }^{\circ} \mathrm{C}\right)$} \\
\cline { 2 - 4 } & 900 & 1000 & 1100 \\
\hline \multicolumn{4}{|c|}{ Main phase (LSFMTO) } \\
\hline Wt. frac (\%) & 58.8 & 71.5 & 75.2 \\
\hline \multicolumn{4}{|c|}{ Other phases } \\
\hline Wt. frac (\%) & 41.2 & 28.5 & 24.8 \\
\hline
\end{tabular}

The morphology of $\quad \mathrm{La}_{0.5} \mathrm{Sr}_{0.5} \mathrm{Fe}_{0.9} \mathrm{Mn}_{0.05} \mathrm{Ti}_{0.05} \mathrm{O}_{3}$ (LSFMTO) sintered systematic various of temperature $900^{\circ} \mathrm{C}, 1000^{\circ} \mathrm{C}$, and $1100^{\circ} \mathrm{C}$ observed with the scanning electron microscope (SEM) as shown in Fig. 2.
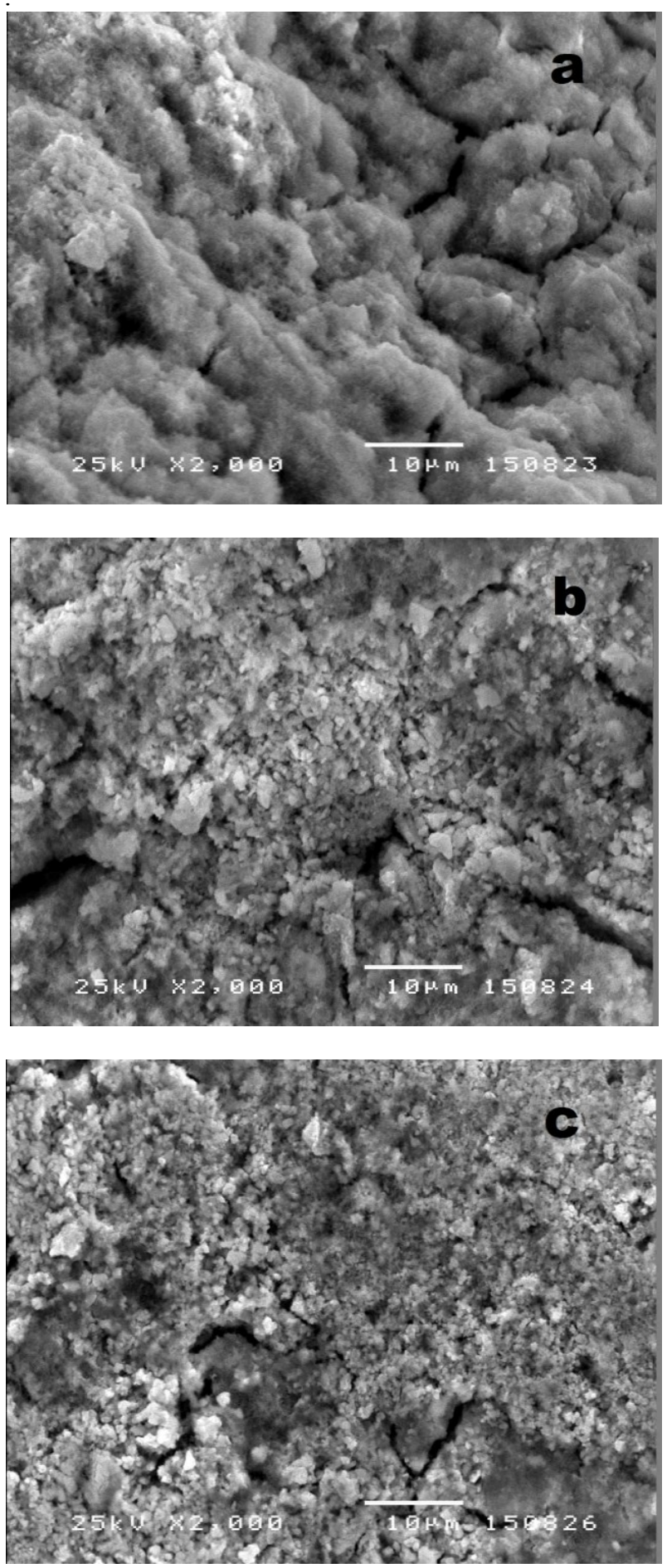

Fig. 2. SEM photographs of $\mathrm{La}_{0.5} \mathrm{Sr}_{0.5} \mathrm{Fe}_{0.9} \mathrm{Mn}_{0.05} \mathrm{Ti}_{0.05} \mathrm{O}_{3}$ (LSFMTO) were calcinated up to $750^{\circ} \mathrm{C}$ for 30 minutes and sintered systematic various of temperature (a). $900{ }^{\circ} \mathrm{C}$, (b). 1000 ${ }^{\circ} \mathrm{C}$, and (c). $1100^{\circ} \mathrm{C}$.

The change of microstructures is observed. This seems to inform that the sintering process determine to form phases and their microstructure. Microstructure of LSFMTO composition appeared in the form of ferroelectric phase 
(La,Sr)(Fe,Mn, Ti) $\mathrm{O}_{3}$ as the majority phase. Some elements of $\mathrm{La}, \mathrm{Sr}$, and $\mathrm{Fe}$ are found in ferroelectric phase with elements $\mathrm{Mn}$ and $\mathrm{Ti}$, in which all of them substitute Fe entirely. In addition, minor elements of $\mathrm{Sr}$ and $\mathrm{Fe}$ formed as ferromagnetic phase and may not substituted by $\mathrm{Mn}$ and Ti. While some La elements found in small quantities as $\mathrm{La}_{2} \mathrm{O}_{3}$. Visually, Figure 1a is differ with Figure $1 \mathrm{~b}$ and $1 \mathrm{c}$ which have the same morphology. It can be concluded that the sintering process of $900^{\circ} \mathrm{C}$ was not enough to form LSFMTO as the expected phase. While images $1 \mathrm{~b}$ and $1 \mathrm{c}$ explained that the establishment of LSFMTO phase is more progressive with increasing the sintering temperature.

\subsection{Magnetic and electric properties}

The magnetic properties determination of LSFMTO through magnetization process at maximum field of $2 \mathrm{~T}$ for all samples yields as permanent magnet hysteresis. Magnetic properties (see Table 2) like saturation magnetization (Ms) and remanent (Mr) have the same value, although small. This suggests that the composition of LSFMTO for all temperature formed as hard magnetic phase of $\mathrm{SrFe}_{12} \mathrm{O}_{19}$. Furthermore, the coercivity which tends to keep as intrinsic magnitude of $\mathrm{SrFe}_{12} \mathrm{O}_{19}$. It is certain that $\mathrm{La}_{0.5} \mathrm{Sr}_{0.5} \mathrm{Fe}_{0.9} \mathrm{Mn}_{0.05} \mathrm{Ti}_{0.05} \mathrm{O}_{3}$ has formed as ferroelectric multi-phase in which the $(\mathrm{La}, \mathrm{Sr})(\mathrm{Fe}, \mathrm{Mn}, \mathrm{Ti}) \mathrm{O}_{3}$ as the main phase and the ferromagnetic properties of $\mathrm{SrFe}_{12} \mathrm{O}_{19}$ and $\mathrm{La}_{2} \mathrm{O}_{3}$ as the second phase.

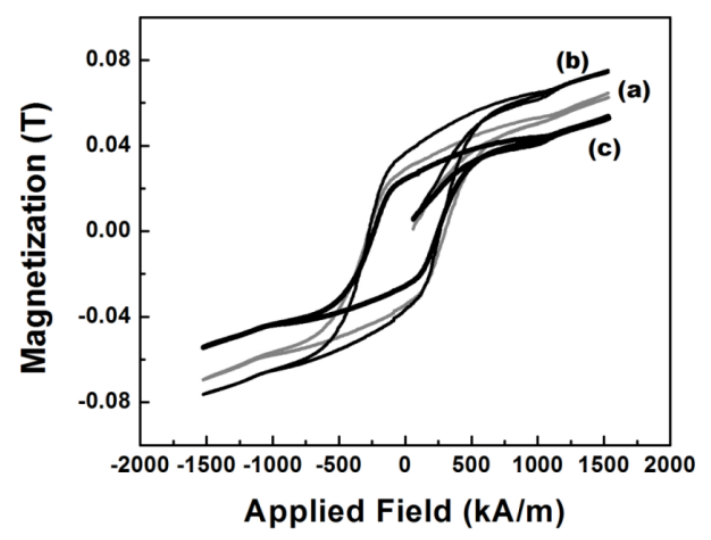

Fig. 3. The magnetic hysteresis loops of LSFMTO that sintered at $900{ }^{\circ} \mathrm{C}(\mathrm{a}), 1000{ }^{\circ} \mathrm{C}(\mathrm{b}), 1100{ }^{\circ} \mathrm{C}$ (c). All of samples show ferromagnetic behaviors at room temperature.

Table 2. Magnetic properties of LSFMTO.

\begin{tabular}{|c|c|c|c|}
\hline $\begin{array}{c}\text { Sintering } \\
\text { Temperature, } \\
\mathrm{T}\left({ }^{\circ} \mathrm{C}\right)\end{array}$ & $\begin{array}{c}\mathrm{H}_{\mathrm{c}} \\
(\mathrm{kA} / \mathrm{m})\end{array}$ & $\begin{array}{c}\mathrm{M}_{\mathrm{r}} \\
(\mathrm{T})\end{array}$ & $\begin{array}{c}\mathrm{M}_{\mathrm{s}} \\
(\mathrm{T})\end{array}$ \\
\hline 900 & 247.6 & 0.029 & 0.054 \\
\hline 1000 & 264.6 & 0.037 & 0.066 \\
\hline 1100 & 235.7 & 0.024 & 0.045 \\
\hline
\end{tabular}

The electric hysteresis loops of LSFMTO at $300 \mathrm{~K}$ were also measured. There are two conditions for the measurement of electrical properties, ie, with and without the magnetic field at $0.12 \mathrm{~T}$ during electrical polarization process (Table 3). The magnetic field results for all samples produced a hysteresis curves. Hysteresis curves of the samples without the magnetic field showed a decline value of electric coercivity (Ec) with increasing sintering temperature. While the saturation polarization $(\mathrm{Pc})$ and the remaining polarization $(\mathrm{Pr})$ tends to remain. For samples measured with the magnetic field shown an increasing in electric coercivity (Ec) in temperature of $900^{\circ} \mathrm{C}$ and $1000^{\circ} \mathrm{C}$ (see Figure $2 \mathrm{a}$ and $2 \mathrm{~b}$ ). While the sample with sintering temperature of $1100^{\circ} \mathrm{C}$ have not change in Ec (Figure 2c). It explains that the temperature of $1100^{\circ} \mathrm{C}$ has increased the weight fraction of the ferroelectric phase $(\mathrm{La}, \mathrm{Sr})(\mathrm{Fe}, \mathrm{Mn}, \mathrm{Ti}) \mathrm{O}_{3}$ as the main phase. While the magnetic phase is decreased (see table 1).
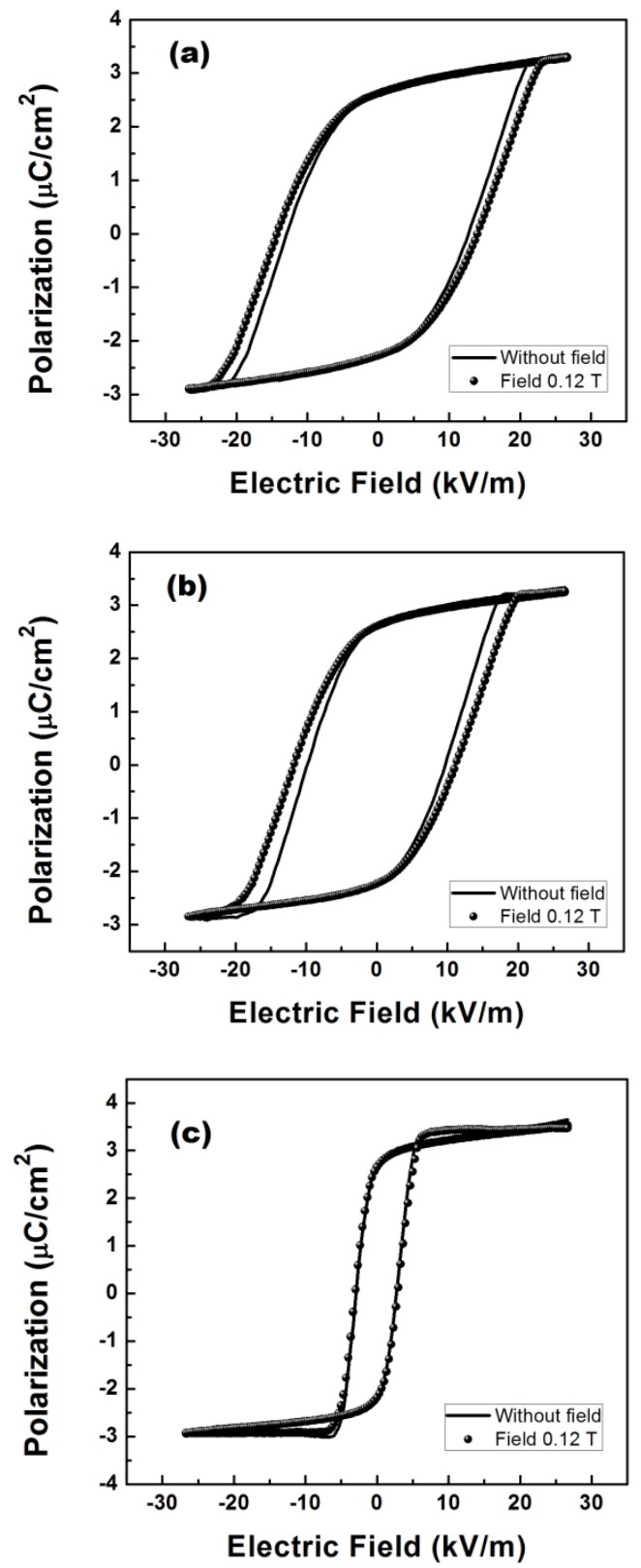

Fig. 4. The electric hysteresis loops of LSFMTO that sintered at $900{ }^{\circ} \mathrm{C}$ (a), $1000{ }^{\circ} \mathrm{C}$ (b), $1100{ }^{\circ} \mathrm{C}$ (c). All of samples show ferroelectric behaviors at room temperature. 
Table 3. Electric properties for LSFMTO.

\begin{tabular}{|c|c|c|c|c|}
\hline Condition & $\begin{array}{c}\mathrm{T} \\
\left({ }^{\circ} \mathrm{C}\right)\end{array}$ & $\begin{array}{c}\mathrm{Ec} \\
(\mathrm{kV} / \mathrm{m})\end{array}$ & $\begin{array}{c}\mathrm{Pr} \\
\left(\mu \mathrm{C} / \mathrm{cm}^{2}\right)\end{array}$ & $\begin{array}{c}\text { Ps } \\
\left(\mu \mathrm{C} / \mathrm{cm}^{2}\right)\end{array}$ \\
\hline \multirow{2}{*}{$\begin{array}{c}\text { No magnetic } \\
\text { field }\end{array}$} & 900 & 12.8 & 2.46 & 3.15 \\
\cline { 2 - 5 } & 1000 & 9.8 & 2.42 & 3.11 \\
\cline { 2 - 5 } & 1100 & 2.8 & 2.43 & 3.29 \\
\hline \multirow{2}{*}{$\begin{array}{c}\text { Magnetic } \\
\text { field 0.12 T }\end{array}$} & 900 & 14.2 & 2.41 & 3.10 \\
\cline { 2 - 5 } & 1000 & 11.5 & 2.42 & 3.05 \\
\cline { 2 - 5 } & 1100 & 3.0 & 2.42 & 3.23 \\
\hline
\end{tabular}

Generally, The hysteresis curve of LSFMTO system shows the electricty coercive (Ec) increases while saturation polarization $(\mathrm{Pc})$ and remanen polarization $(\mathrm{Pr})$ are tendency constant at the magnetic strength of $0.12 \mathrm{~T}$ at temperature of $900^{\circ} \mathrm{C}$ dan $1000^{\circ} \mathrm{C}$. However, at temperatures of $1100^{\circ} \mathrm{C}$ has no changes in electrical coercivity (Ec) (Fig. 5).

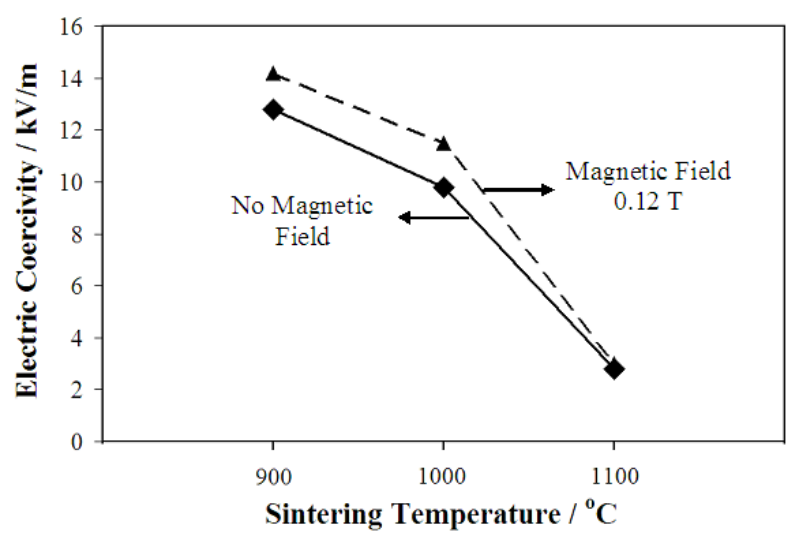

Fig. 5. The influence of magnetic field $0.12 \mathrm{~T}$ on the enhancement of electic coercivity of LSFMTO after sintering process at $900^{\circ} \mathrm{C}, 1000^{\circ} \mathrm{C}, 1100^{\circ} \mathrm{C}$ for 30 minutes.

\section{Conclusions}

For the $\mathrm{La}_{0.5} \mathrm{Sr}_{0.5} \mathrm{Fe}_{0.9} \mathrm{Mn}_{0.05} \mathrm{Ti}_{0.05} \mathrm{O}_{3}$ samples systems prepared by ultrasonic mixing method have found multi phases that they are consists of ferroelectric phase of $(\mathrm{La}, \mathrm{Sr})(\mathrm{Fe}, \mathrm{Mn}, \mathrm{Ti}) \mathrm{O}_{3}$, ferromagnetic phase of $\mathrm{SrFe}_{12} 0_{19}$ and minor phase $\mathrm{La}_{2} \mathrm{O}_{3}$. The increasing in sintering temperature will increase the weight fraction of the main phase $(\mathrm{La}, \mathrm{Sr})(\mathrm{Fe}, \mathrm{Mn}, \mathrm{Ti}) \mathrm{O}_{3}$ and decreasing the second phase. The saturation polarization (Ps) and remanent polarization $(\mathrm{Pr})$ tends to stable at any temperature sintering and measurement conditions. We believed that our work has showed a new innovation in LSFMTO system and the results are very potential for multiferroic materials applications.

This work was funded by Research grant 2018 of Universitas Negeri Jakarta, Indonesia.

\section{References}

1. C. Murugesan, J. Won, J. Kim, and S. Su, "Effects of La- and V-doping on structural, electrical and multiferroic properties of $\mathrm{Bi} 6 \mathrm{Fe} 2 \mathrm{Ti} 3 \mathrm{O} 18$ thin fi lms," Ceram. Int., vol. 40, no. 7, pp. 10649-10655, (2014).

2. M. Etier, C. Schmitz-antoniak, S. Salamon, H. Trivedi, and Y. Gao, "ScienceDirect Magnetoelectric coupling on multiferroic cobalt ferrite - barium titanate ceramic composites with different connectivity schemes," ACTA Mater., vol. 90, pp. 19, (2015).

3. S. Katlakunta, P. Raju, S. Singh, S. Srinath, R. Sandhya, P. Kuruva, and S. Ramana, "Multiferroic properties of microwave sintered," Phys. B Phys. Condens. Matter, vol. 448, pp. 323-326, (2014).

4. S. K. Das, P. P. Rout, S. K. Pradhan, and B. K. Roul, "Effect of equiproprotional substitution of $\mathrm{Zn}$ and $\mathrm{Mn}$ in BaTiO 3 ceramic - An index to multiferroic applications," vol. 1, no. 3, pp. 241-248, (2012).

5. G. V Duong, R. Groessinger, and R. S. Turtelli, "Driving mechanism for magnetoelectric effect in CoFe 2 O 4 - BaTiO 3 multiferroic composite," vol. 310, pp. 1157-1159, (2007).

6. J. T. Zhang, X. M. Lu, J. Zhou, H. Sun, F. Z. Huang, and J. S. Zhu, "Magnetic properties and origins of ferroelectric polarization in multiferroic $\mathrm{CaMn} 7 \mathrm{O}$ 12," vol. 75127, pp. 1-6, (2013).

7. S. Layek and H. C. Verma, "Magnetic and dielectric properties of multiferroic $\mathrm{BiFeO} 3$ nanoparticles synthesized by a novel citrate combustion method," vol. 3, no. 6, pp. 533-538, (2012).

8. L. Shu, J. Hu, Y. Gao, L. Wu, J. Ma, Y. H. Lin, and C. W. Nan, “Applied Surface Science Voltage-driven hysteretic changes in magnetization in multiferroic Co / BTO composite thin films," Appl. Surf. Sci., vol. 314, pp. 599-602, (2014).

9. J. Ma, J. Hu, Z. Li, and C. Nan, "Recent Progress in Multiferroic Magnetoelectric Composites: from Bulk to Thin Films," pp. 1-26, (2011).

10. C. H. Sim, Z. Z. Pan, and J. Wang, "Residual stress and magnetic behavior of multiferroic $\mathrm{CoFe} 2 \mathrm{O} 4$ / $\mathrm{Pb}$ ( Zr 0 . $52 \mathrm{Ti} 0.48$ ) O 3 thin films Residual stress and magnetic behavior of multiferroic," vol. 84113, no. 2009, pp. 0-7, (2010).

11. L. Sebastian, A. K. Shukla, and J. Gopalakrishnan, "metal-substituted derivatives of lanthanum strontium - gallium - magnesium ( LSGM ) perovskite oxide ion conductor," vol. 23, no. 3, pp. 169-173, (2000).

12. S. La and S. Mno, "Magnetic, Electrical Transport and Impedance Spectroscopy Studies on Ti," vol. 38, no. 5, pp. 673-678, (2009).

13. R. S. D. La-ca, "Magnetoresistive and Magnetic Properties of Films," vol. 36, no. 5, pp. 2933-2935, (2000).

14. M. S. Kim, J. B. Yang, Q. Cai, X. D. Zhou, W. J. James, W. B. Yelon, P. E. Parris, D. Buddhikot, and S. K. Malik, "Structure, magnetic , and transport properties of Ti-substituted La 0 . $7 \mathrm{Sr} 0$. $3 \mathrm{MnO} 3$," pp. 1-8, (2005).

15. C. Zhang, J. S. Kim, B. H. Kim, and Y. W. Park, "Phase separation in La 1.85-1.5," vol. 24505, no. February, pp. 1-6, (2004).

16. "Colossal enhancement of magnetoresistance," vol. 27003, pp. 0-5, (2008). 
17. L. Sr, Y. L. Cheng, J. M. Ã. Dai, D. J. Wu, and Y. P. Sun, "Journal of Magnetism and Magnetic Materials Electromagnetic and microwave absorption properties of carbonyl iron /," J. Magn. Magn. Mater., vol. 322, no. 1, pp. 97-101, (2010).

18. F. C. Zhang, W. Z. Gong, C. Cai, B. Xu, X. G. Qiu, R. Vanfleet, L. Chow, and B. R. Zhao, "Room temperature ultrahigh magnetoresistance in La 0.67 Sr $0.33 \mathrm{MnO} 3$ thin films with ordered nanometer structure," vol. 131, pp. 271-274, (2004).

19. S. Kar, J. Sarkar, B. Ghosh, and A. K. Raychaudhuri, "Spatially resolved study of electronic transport through grain boundaries in nanostructured films," pp. 1-9, (2006). 